\title{
Temporary amniotic membrane patching for acute chemical burns
}

A Kobayashi', Y Shirao', T Yoshita', K Yagami', Y Segawa' ${ }^{1}$ K Kawasaki², M Shozu² and SCG Tseng ${ }^{3}$

\begin{abstract}
Purpose To describe the surgical technique, and its usefulness, of temporary amniotic membrane patching (AMP) in the acute phase of ocular chemical injury. Methods Temporary AMP with modification in suture placement was performed on five eyes of five consecutive patients inflicted with acute chemical injury having a greater than grade II injury by the Roper-Hall classification.

Results All patients reported herein presented with a large epithelial defect on the cornea and conjunctiva. Case 3 was classified as grade III while the other four cases were classified as grade II. The causative chemical agents were anhydrous acetic acid in Case 1, calcium oxide in Case 2 , sodium hydroxide in Case 3 , sodium silicate in Case 4 , and sulphuric acid in Case 5. All cases experienced rapid relief of pain after AMP.

Epithelialization of the cornea with improvement of visual acuity was observed in all cases when the amniotic membrane was removed within 2 weeks after surgery. During the mean follow-up of $\mathbf{1 9 . 6}$ months, the ocular surface remained stable and no cicatricial complications were noted.

Conclusions These results suggest that immediate AMP is quite useful for managing moderately severe acute ocular chemical injury by facilitating rapid epithelialization and pain relief, and securing ocular surface integrity. Eye (2003) 17, 149-158. doi:10.1038/

sj.eye. 6700316
\end{abstract}

Keywords: amniotic membrane patching; amniotic membrane; acute chemical burn; alkali burn; acid burn; cornea

\section{Introduction}

Ocular chemical injury remains one of the most difficult ocular emergencies. The prognosis for a burned eye depends not only on the severity of the injury but also on the rapidity and mode of treatment. Recently, amniotic membrane patching (AMP) has been shown to be useful towards achieving a desirable outcome for acute chemical burns. ${ }^{1-3}$ Herein we show the clinical outcome of temporary AMP in five consecutive patients with acute chemical burns of greater than grade II of the Roper-Hall classification ${ }^{4}$ using a modified suture placement to prevent early detachment of the amniotic membrane (AM).

\section{Materials and methods}

\section{Preparation of human AM}

The preparation and clinical use of human AM was approved by the Ethical Committee of Kanazawa University Graduate School of Medical Science. The method of preparation followed what was previously reported. ${ }^{5-7}$ In brief, after written informed consent was obtained, the human placenta was obtained shortly after elective caesarean delivery from a donor mother. Human immunodeficiency virus, hepatitis virus type $B$, hepatitis virus type $C$, and syphilis were serologically excluded. Under a lamellar-flow hood, the placenta was cleaned of blood clots with sterile saline containing $50 \mu \mathrm{g} / \mathrm{ml}$ of penicillin, $50 \mu \mathrm{g} / \mathrm{ml}$ of streptomycin, $100 \mu \mathrm{g} / \mathrm{ml}$ of neomycin and $1.25 \mu \mathrm{g} / \mathrm{ml}$ of amphotericin B. The amnion was separated from the rest of the chorion by blunt dissection through the potential spaces situated between these two tissues and then spread, with the epithelium/basement membrane surface up, onto a sheet of nitrocellulose paper. The paper, with the adherent amniotic membrane on it, was then cut into small $(\mathrm{ca} 5.0 \mathrm{~cm} \times 5.0 \mathrm{~cm})$ pieces, and stored at $-80^{\circ} \mathrm{C}$ in a sterile vial containing Dulbecco's modified Eagle's medium (DMEM) and glycerol in the ratio of $1: 1(\mathrm{v} / \mathrm{v})$.

\author{
${ }^{1}$ Department of \\ Ophthalmology \\ Kanazawa University \\ Graduate School of \\ Medical Science \\ Kanazawa, Japan \\ ${ }^{2}$ Department of Obstetrics \\ and Gynecology \\ Kanazawa University \\ Graduate School of \\ Medical Science \\ Kanazawa, Japan
}

${ }^{3}$ Ocular Surface Center and Ocular Surface Research and Education Foundation Miami, FL, USA

Correspondence:

A Kobayashi

Department of

Ophthalmology

Kanazawa University

Graduate School of

Medical Science

13-1 Takara-machi

Kanazawa

Ishikawa 920-8641

Japan

Tel: + 81-76-265-2403

Fax: + 81-76-222-9660

E-mail: kobaya@

kenroku.kanazawa-u.ac.jp

Received: 19 November 2001

Accepted in revised form: 10 June 2002 


\section{Surgical technique}

Details of the clinical course of chemical ocular injury without AMP, in addition to surgical procedures of AMP, as well as alternative methods to AMP and expected outcome of AMP based on published data ${ }^{4,8-13}$ were fully explained. Subsequently, written informed consent was obtained from each patient.

Before operation, a mixture of $2 \%$ lidocaine hydrochloride and bupivacaine hydrochloride in the ratio of $1: 1(\mathrm{v} / \mathrm{v})$ was injected subcutaneously into lower and upper eyelids as well as lower and upper fornices. When the patient was ready, one or two pieces of AM $(3.0 \times 4.0 \mathrm{~cm})$ were removed from the storage medium, and the edge of the nitrocellulose filter paper was partially peeled off. The AM was then transferred to the recipient eye with the filter membrane still attached.
The AM was anchored to the lower lid margins by 10-0 nylon running sutures (Figure $1 \mathrm{a}$ and $\mathrm{b}$ ). Then, the AM was secured onto the palpebral conjunctiva with two transpalpebral mattress sutures of 6-0 polypropylene (Prolin) with bolsters made by \#40 silicon bands, each suture being placed near each canthus of the lid (Figure 1c-e). As shown in Figure 1e, bolsters were placed only outside of the skin. Then, AM was fixed to the episclera with a purse-string 10-0 nylon suture at the limbus (Figure $1 \mathrm{f}$ and $\mathrm{g}$ ). Then, the above-described same procedure was performed to the upper eyelid (Figure 1h). Thus, all of the ocular surface including the injured as well as the uninjured cornea and conjunctiva was covered by one or two layers of AM. Our modifications of suture placement were as follows (Figure 2). First, we used running instead of interrupted sutures to anchor the AM to the lid margins.
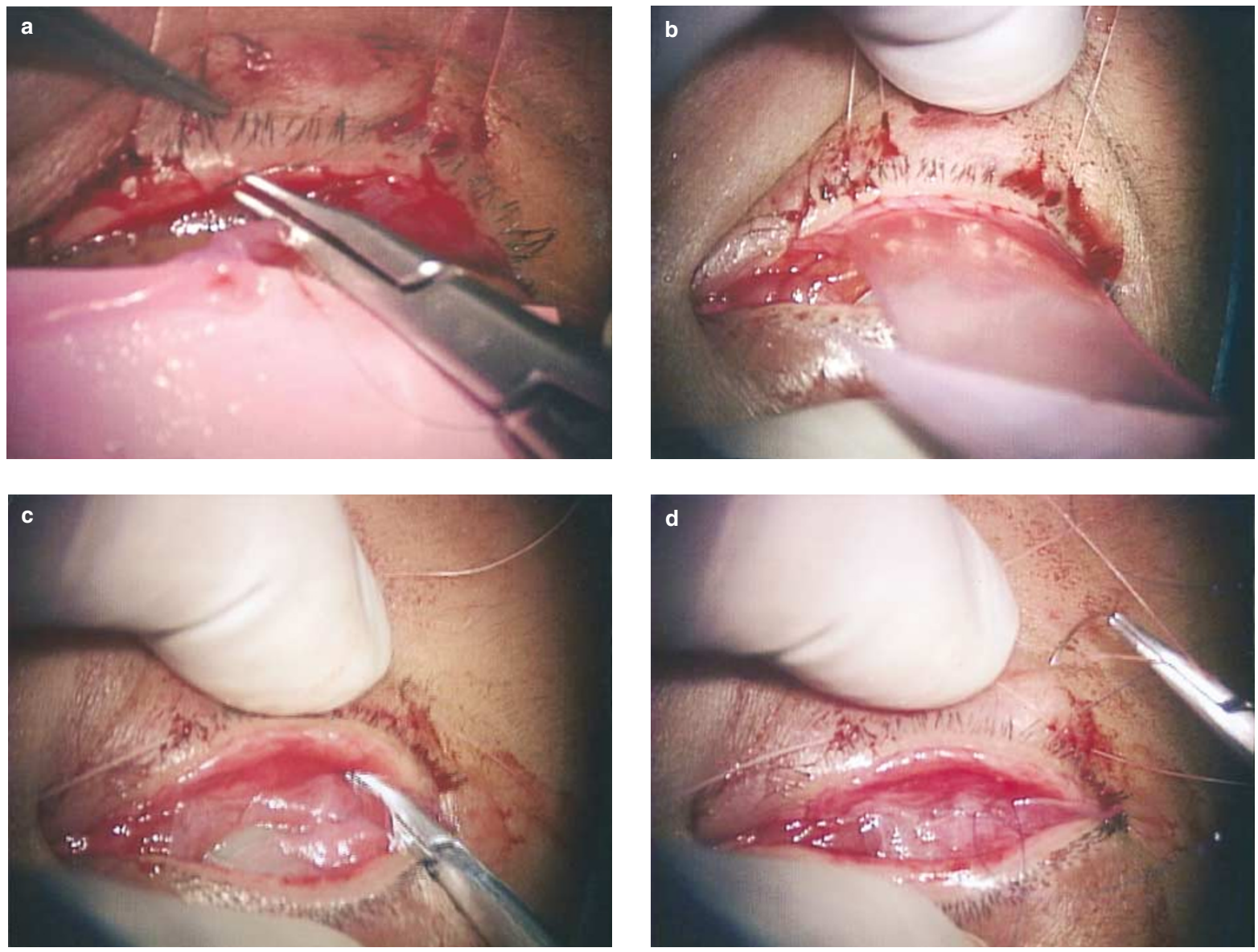

Figure 1 Representative steps of AMP in Case 3. The edge of the nitrocellulose filter paper which carries AM was partially peeled off. The AM was then transferred to the recipient eye with the filter membrane still attached. The AM was anchored to the lower lid margins by 10-0 nylon running sutures followed by peeling off the filter membrane ( $a$ and $b$ ). The AM was then secured onto the palpebral conjunctiva with two transpalpebral mattress sutures with bolsters being placed outside of the skin near each canthus of the lid (c and e). The AM was fixed to the episclera with a purse-string 10-0 nylon suture at 1-2 mm from the limbus (f and $\mathrm{g}$ ). Thus, all of the ocular surface was covered by the AM. Then, the above-described same procedure was performed to the upper eyelid (h). 

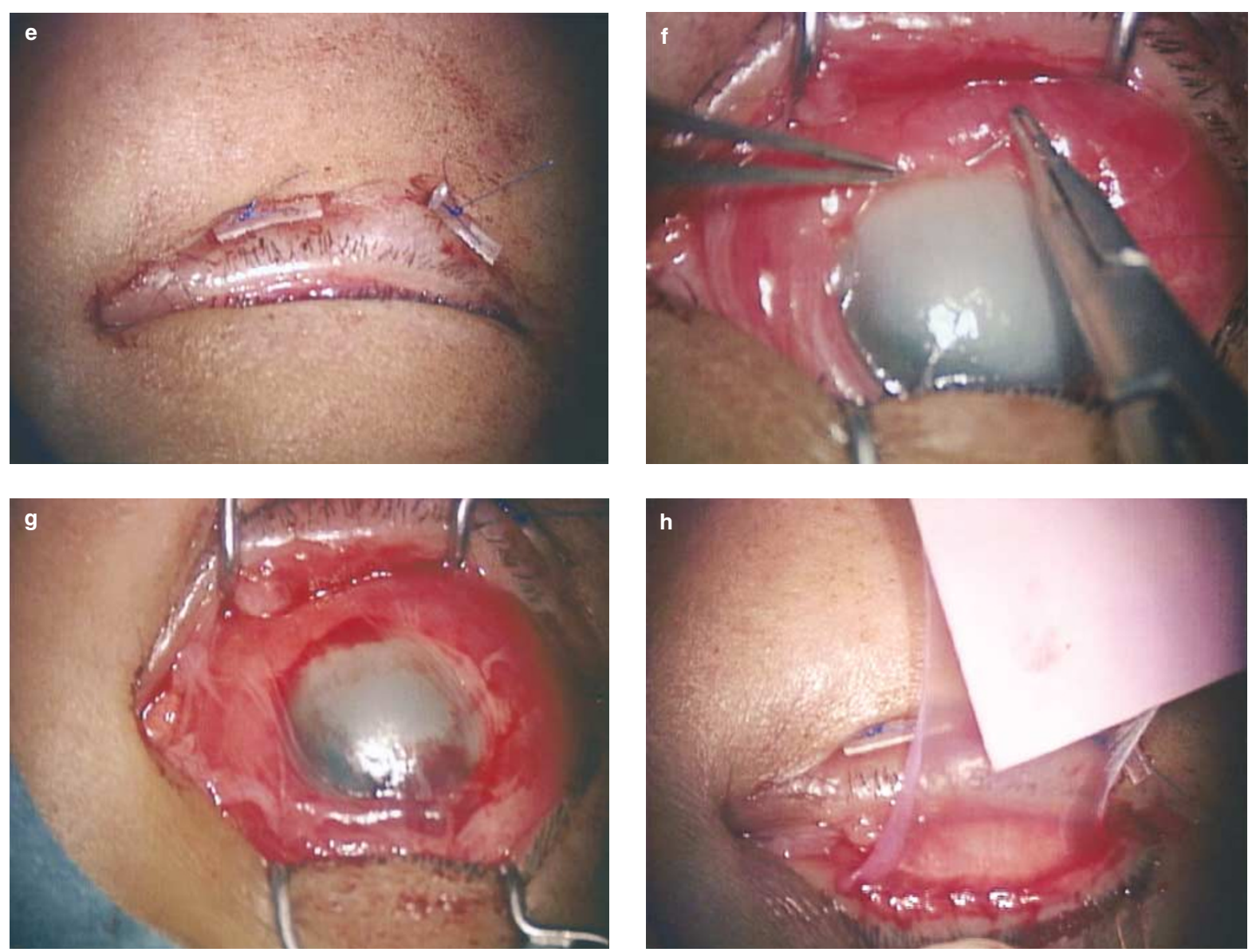

Figure 1 continued

Second, we fixed the AM to the episclera with a purse-string 10-0 nylon suture 1 or $2 \mathrm{~mm}$ from the limbus to prevent an excess of redundant AM tissue extending from the palpebral fissure. The AM was placed with the basement membrane side up in all cases and was removed within 2 weeks after AMP.

Postoperative medications included topical $0.3 \%$ ofloxacin and $0.1 \%$ betamethasone four times daily with oral prednisolone starting at $30 \mathrm{mg} /$ day and tapering off in 12 days.

\section{Results}

Five consecutive patients who visited Kanazawa University Hospital during the period from June 2000 to May 2001 with acute chemical burns of greater than grade II injury by Roper-Hall classification ${ }^{4}$ were enrolled in this study, and they underwent the abovementioned temporary AMP. Cases 1 and 3 visited our hospital directly, while Cases 2, 4 and 5 were referred to our hospital. The demographic data are summarized in Table 1.

\section{Case 1}

A 29-year-old male presented with an acute ocular burn in his right eye from anhydrous acetic acid, and complained of constant irritation, pain and decreased visual acuity (20/100). The corneal epithelium was largely denuded except for a small island of the upper limbal epithelium (Figure $3 a$ and $b$ ). There was a faint corneal stromal haze as well as a large area of conjunctival epithelial defect with less than $1 / 3$ of perilimbal ischaemia. This injury was classified as grade II. The upper part of the conjunctiva was severely injected, while the lower part of the conjunctiva exhibited an ischaemic change. Also, a loss of Palisade of Vogt (POV) was observed in the lower part of the limbus. The eye was irrigated with a large amount of saline, the necrotic tissue was removed, and normalization of $\mathrm{pH}$ was confirmed. Despite the use of topical antibiotics and steroid eye drops, no sign of epithelialization was noted for 3 days and the clinical situation worsened. AMP was performed 4 days after the first treatment (Figure $3 \mathrm{c}$ and d). Ocular irritation and pain were instantaneously 


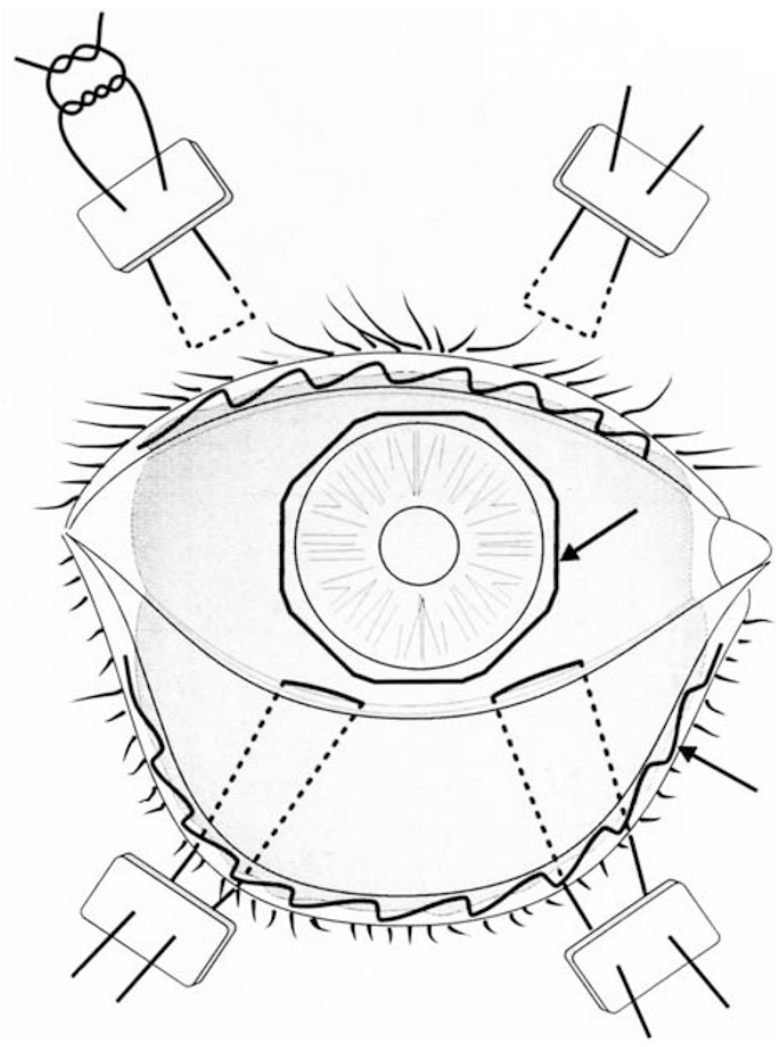

Figure 2 Schematic drawing of AMP for acute chemical injury. Arrows indicate the additional suture placement. See 'Surgical technique' for more details.

relieved, and complete epithelialization was noted as early as 7 days after surgery when the AM was removed. In this case, the front line of corneal epithelial cell migration was slightly observed through the opaque AM. As a result, conjunctival injection was markedly reduced. Visual acuity improved from 20/100 to 20/16 after 1 month (Figure $3 e$ and $\mathrm{f}$ ), and the corneal surface remained smooth after 16 months of follow-up.

\section{Case 2}

A 24-year-old male presented with an acute ocular burn caused by calcium oxide (slaked lime) in his right eye, and complained of severe ocular irritation, pain and a decrease in visual acuity $(20 / 100)$. More than $90 \%$ of the corneal surface, the large area of bulbar, as well as the palpebral conjunctival surface were eroded. This case was classified as grade II, as less than one-third of the limbus was ischaemic. First, conventional therapy, including intensive irrigation by saline, was performed. Then, AMP was performed on the same day as the injury. One day after AMP the severe ocular irritation and pain disappeared. Epithelialization of the cornea was observed when the AM was removed 10 days after surgery. In this case, as seen in Case 1, the front line of corneal epithelial cell migration was slightly observed through the opaque AM, with the corneal epithelialization believed to be completed on day 5 after AMP. A bandage soft contact lens (BSCL) was applied for 2 weeks until the superficial punctate keratitis (SPK) disappeared. Visual acuity improved from 20/100 to 20/ 16 with an intact corneal and conjunctival surface observed after 14 months of follow-up.

\section{Case 3}

A 32-year-old male presented with an acute ocular burn from $10 \%$ sodium hydroxide in his right eye, and a complaint of constant irritation and blurred vision (20/ 400). Despite immediate irrigation with a large amount of saline and the use of topical antibiotics and steroid eye drops five times daily, epithelialization was not noted for 3 days and he was referred to our hospital. The corneal epithelium was largely denuded except for a small (less than one-quarter) island of the upper limbal epithelium (Figure $4 \mathrm{a}-\mathrm{c}$ ). The lower conjunctiva was ischaemic with a loss of POV at the limbus. More than half of the corneal stroma was opaque and the iris details could be discerned only through the upper 'less injured' cornea. Marked pseudomembrane was formed on the conjunctiva with considerable mucus discharge. This case was classified as grade III. Intraocular pressure was not elevated but prophylactic oral acetazolamide was given for 10 days. AMP was performed 4 days after the injury (Figure 4d). Ocular irritation was rapidly relieved the day after surgery. Corneal and conjunctival epithelialization was observed when the AM was removed 14 days after surgery and replaced by a BSCL. Visual acuity improved from 20/400 to 20/16 after 3 weeks with an intact corneal and conjunctival surface with mild stromal opacity. After 14 months of follow-up, no cicatricial complication was noted; however, conjunctival ingrowth and a delayed fluorescein staining inferiory was noted (Figure $4 \mathrm{e}$ and f).

\section{Case 4}

A 24-year-old male presented with an acute ocular burn from sodium silicate in his left eye and a complaint of intense pain and blurred vision (20/40). His eyelids were oedematous and swollen. The corneal epithelium was largely defective except for small islands of the limbal epithelium. The upper part of the limbus was ischaemic with the loss of POV. Corneal stroma was transparent without any haze. This case was classified as grade II. AMP was performed on the day of injury to reduce the intolerable pain and to promote epithelialization. The 
Table 1 Summary of the patients

\begin{tabular}{|c|c|c|c|c|c|c|c|c|c|}
\hline \multirow[t]{2}{*}{$\begin{array}{l}\text { Patient } \\
\text { no. }\end{array}$} & \multirow[t]{2}{*}{ Sex/age } & \multirow[t]{2}{*}{ Grade $^{\mathrm{a}}$} & \multirow[t]{2}{*}{ Agent/eye } & \multirow{2}{*}{$\begin{array}{l}\text { Time between } \\
\text { injury and } \\
\text { surgery }\end{array}$} & \multirow{2}{*}{$\begin{array}{l}\text { Time to re- } \\
\text { epithelialization } \\
\text { (days) }\end{array}$} & \multicolumn{2}{|c|}{ Visual acuity } & \multirow[t]{2}{*}{$\begin{array}{l}\text { Follow-up } \\
\text { (months) }\end{array}$} & \multirow[t]{2}{*}{ Key findings } \\
\hline & & & & & & Before & After & & \\
\hline 1 & Male/29 & II & $\begin{array}{l}\text { Anhydrous } \\
\text { acetic acid } \\
\text { (acid)/OD }\end{array}$ & 4 days & $\begin{array}{l}\text { C:7 } \\
\mathrm{J}: 7\end{array}$ & $20 / 100$ & $20 / 16$ & 24 & $\begin{array}{l}\text { C: } 100 \% \text { ED, L: } 90 \% \text { ED, ischaemic in less } \\
\text { than } 1 / 3 \text { limbus } \\
\text { J: necrosis in inferior and nasal bulbar } \\
\text { conjunctiva and upper and lower palpebral } \\
\text { conjunctiva }\end{array}$ \\
\hline 2 & Male/24 & II & $\begin{array}{l}\text { Calcium oxide } \\
\text { (alkali)/OD }\end{array}$ & $10 \mathrm{~h}$ & $\begin{array}{l}\text { C: } 5 \\
\mathrm{~J}: 17\end{array}$ & $20 / 100$ & $20 / 16$ & 22 & $\begin{array}{l}\text { C: } 90 \% \text { ED, L: } 70 \% \mathrm{ED} \text {, ischaemia in less } \\
\text { than } 1 / 3 \text { limbus } \\
\text { J: large ED in bulbar conjunctiva }\end{array}$ \\
\hline 3 & Male/32 & III & $\begin{array}{l}\text { Sodium } \\
\text { hydroxide } \\
\text { (alkali)/OD }\end{array}$ & 4 days & $\begin{array}{l}\mathrm{C}: 14^{\mathrm{b}} \\
\mathrm{J}: 14^{\mathrm{b}}\end{array}$ & $20 / 400$ & $20 / 16$ & 22 & $\begin{array}{l}\text { C: } 100 \%, \text { L: } 90 \% \text { ED, About one-half of the } \\
\text { limbus was ischaemic. J: large ED in bulbar } \\
\text { and upper bulbar conjunctiva }\end{array}$ \\
\hline 4 & Male/24 & II & $\begin{array}{l}\text { Sodium silicate } \\
\text { (alkali)/OS }\end{array}$ & $12 \mathrm{~h}$ & $\begin{array}{l}\mathrm{C}: 8^{\mathrm{b}} \\
\mathrm{J}: 8^{\mathrm{b}}\end{array}$ & $20 / 40$ & $20 / 20$ & 16 & $\begin{array}{l}\text { C: } 100 \% \text { ED, L: } 80 \% \text { ED, ischaemic in less } \\
\text { than } 1 / 3 \text { limbus } \\
\text { J: large ED in bulbar conjunctiva. }\end{array}$ \\
\hline 5 & Male/46 & II & $\begin{array}{l}\text { Sulphuric acid } \\
\text { (acid)/OD }\end{array}$ & 6 days & $\begin{array}{l}\text { C: } 14^{b} \\
\text { J: } 18\end{array}$ & $20 / 100$ & $25 / 20$ & 14 & $\begin{array}{l}\text { C: } 100 \% \text { ED, L: } 75 \% \text { ED, ischaemia in less } \\
\text { than } 1 / 3 \text { limbus } \\
\text { J: large ED and ischaemia in upper bulbar } \\
\text { conjunctiva }\end{array}$ \\
\hline
\end{tabular}

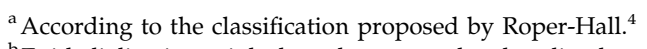

${ }^{\mathrm{b}}$ Epithelialization might have been completed earlier, but could not be observed until removal of AMP.

C: cornea; L: limbus; J: conjunctiva; ED: epithelial defect. 

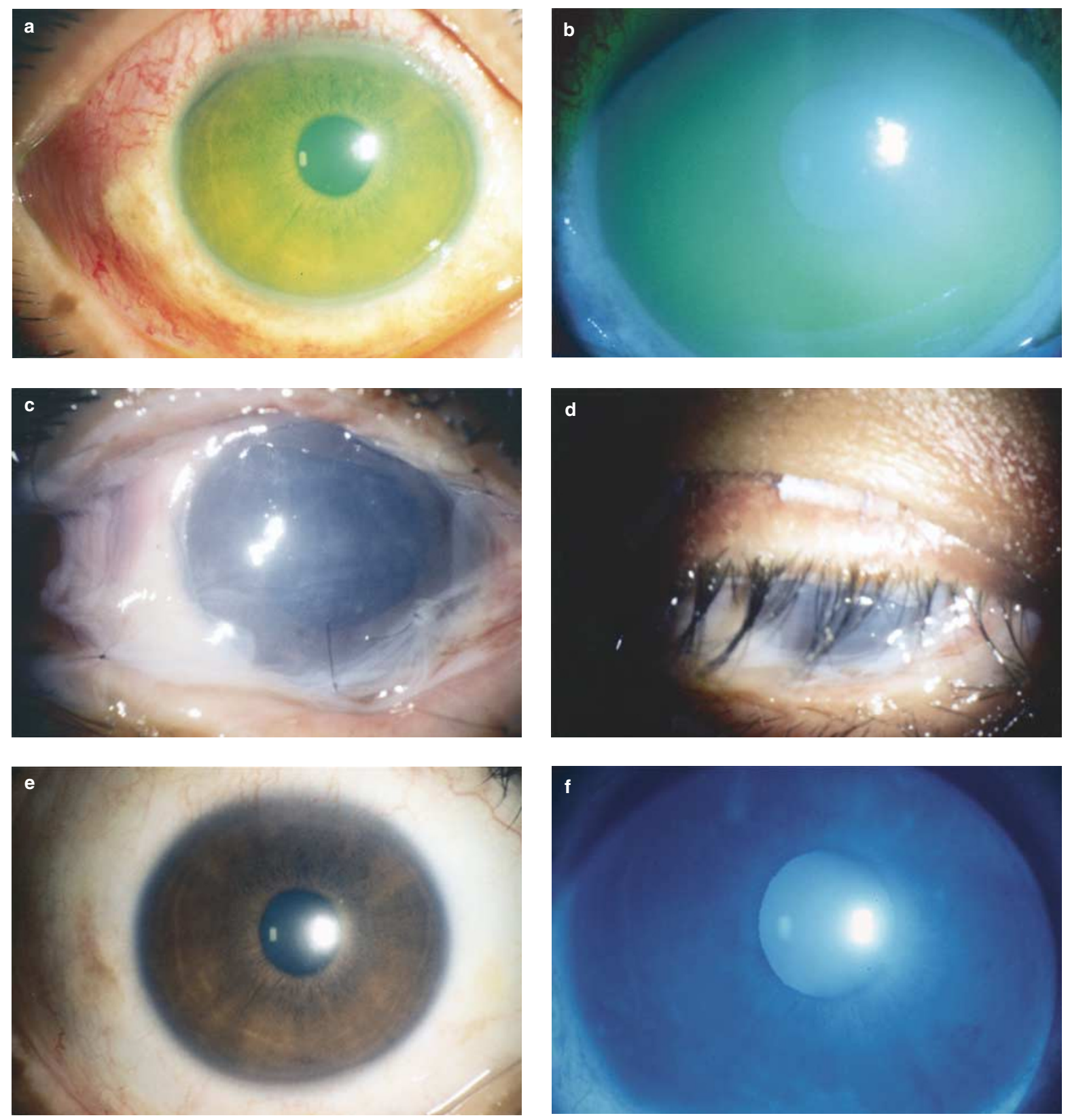

Figure 3 Case 1. (a) Before AMP. Entire corneal epithelia and a large area of conjunctival epithelia were denuded. (b) Fluorescein staining before AMT. (c) one day after AMT. Entire cornea and conjunctiva were covered by AM. (d) Transpalpebral mattress sutures with bolsters that secure AM onto the palpebral conjunctiva. (e and f) One month after AMP. Corneal and conjunctival surface is smooth and quiet.

ocular pain was rapidly relieved the day after surgery. Corneal epithelialization was observed after the $\mathrm{AM}$ was removed 8 days after surgery and replaced with a BSCL. Visual acuity improved from 20/ 40 to 20/20 after 3 weeks. After 8 months of follow-up, the ocular surface remained smooth without any complications.

\section{Case 5}

A 46-year-old male suffered a bilateral acid injury caused by a splash of $75 \%$ sulphuric acid onto his face and into the right eye. After intensive irrigation, he was referred to our eye clinic with a complaint of decreased vision $(20 / 100)$ and pain. Ocular examination revealed a large 

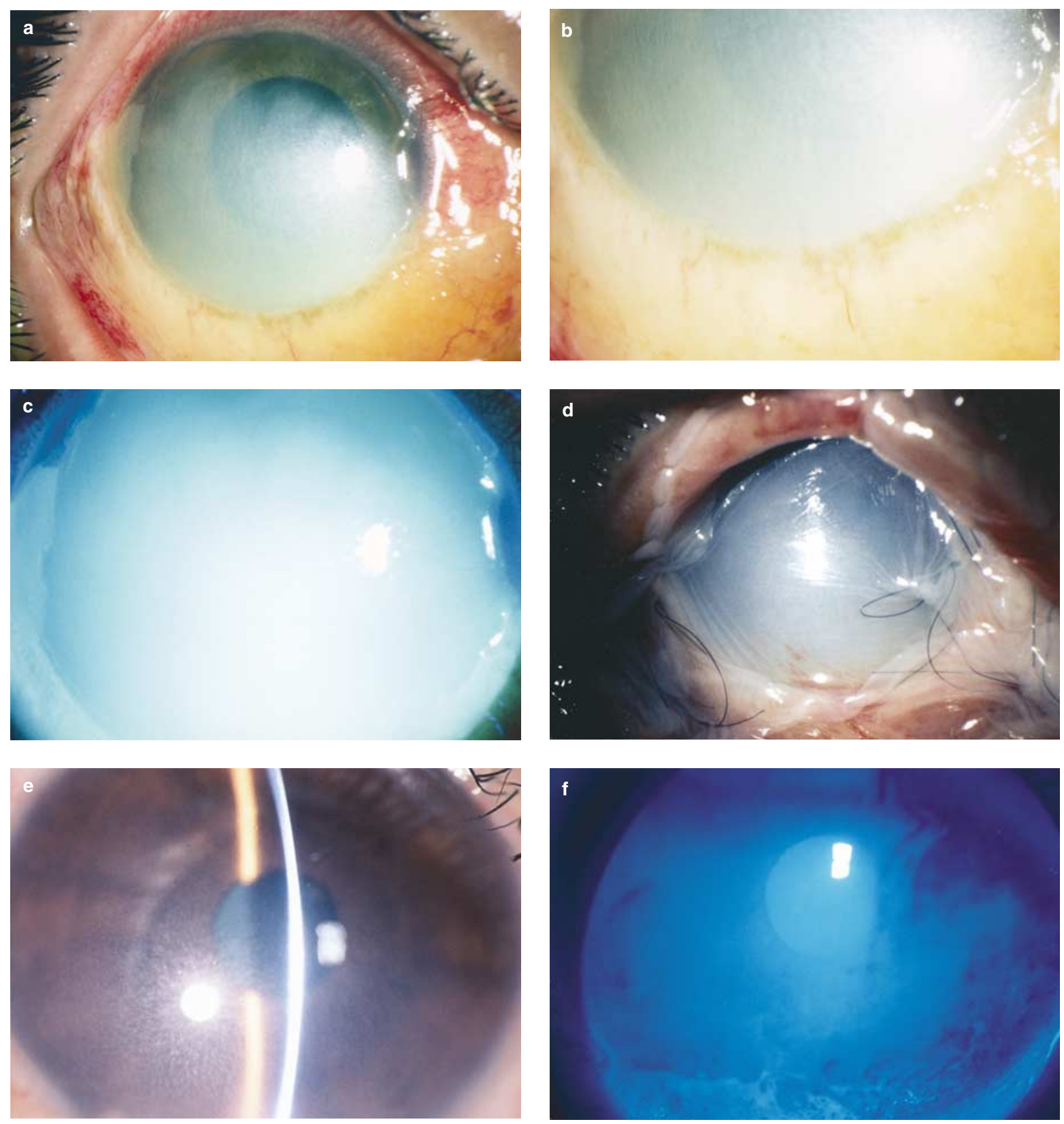

Figure 4 Case 3. (a-c) Before AMP. The entire corneal epithelia and a large area of the conjunctival epithelia were denuded. (d) One day after AMP. Entire cornea and conjunctiva were covered by the AM. (e and f) Six months after AMP. Corneal and conjunctival surface is smooth and quiet.

corneal and conjunctival epithelial defect with severe conjunctival chemosis (Figure $5 \mathrm{a}$ and b). The corneal stroma was slightly hazy with many Descemet's folds, but iris details were visible. The upper half of the limbus and conjunctiva were ischaemic with a loss of POV; this case was classified as grade II. Intraocular pressure was $43 \mathrm{mmHg}$ in his right eye, which was reduced by oral acetazoramide and a topical $\beta$-blocker within 2 days. As the corneal defect was not healed after 3 days, AMP was performed four days after the injury. The pain and discomfort were reduced the day after the operation. Corneal epithelialization was observed when the AM was removed 14 days after surgery and replaced with a BSCL. Complete conjunctival epithelialization was observed on day 18 after the operation. Visual acuity improved from 20/100 to 25/20 within 6 weeks. After 6 months of follow-up, the ocular surface remained smooth without any complications (Figure 5c and d). 

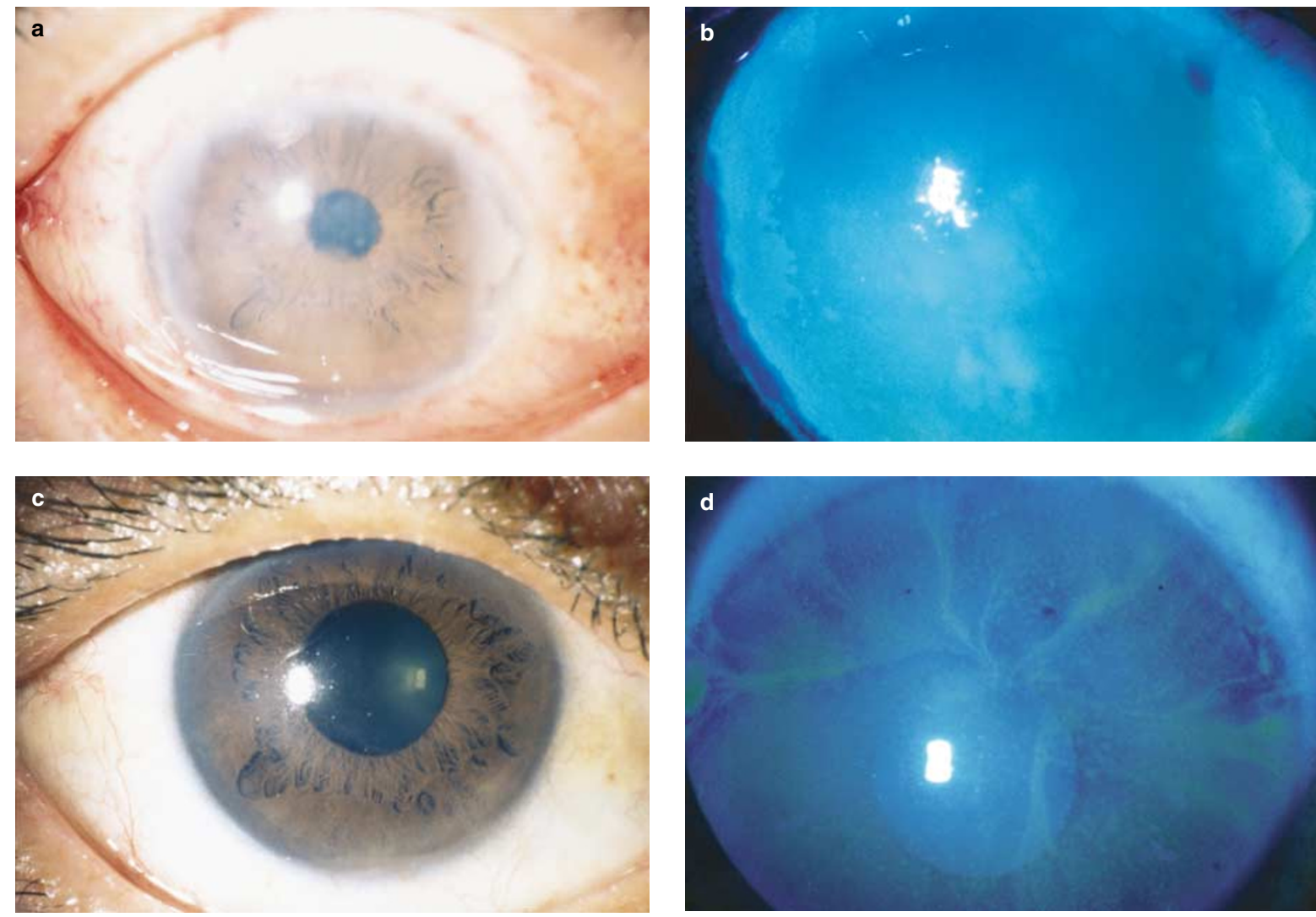

Figure 5 Case 5. (a and b) Before AMP. A large corneal epithelial defect, except for a small island of the lower limbal epithelium, was observed. Upper half of the limbus showed ischaemic changes. (c and d) Six weeks after AMP. The ocular surface remained stable, and no cicatricial complications were noted. Whirling pattern of fluorescein staining disappeared 1 week later.

\section{Discussion}

We report herein the clinical outcome of five consecutive patients inflicted with acute chemical burns and treated by temporary AMP with modified suture placement. With the exception of Case 3, which was classified as grade III, the other four cases were classified as grade II injuries. The causative chemical agents were anhydrous acetic acid in Case 1, calcium oxide in Case 2, sodium hydroxide in Case 3, sodium silicate in Case 4, and sulphuric acid in Case 5. All cases experienced a rapid relief of pain. Epithelialization of the cornea with improved visual acuity was observed in all cases after the AM was removed within 2 weeks following surgery. During the mean follow-up of 19.6 months, the ocular surface remained stable and no cicatricial complication was noted.

When the AM is used as a patch, it is necessary to make sure that the AM is well fastened on the ocular surface, although AMP may not need to be as tight as amniotic membrane transplantation (AMT) where the AM is used as a graft. This concern was raised because excessively redundant AM might be detached from the interpalpebral fissure by eye rubbing and carry the risk of infection. Actually one of the 13 cases reported by Meller $e t a l^{2}$ showed a detached AM after 1 week as a result of constant rubbing of the eye. To prevent the early detachment from the ocular surface, a purse-string running suture was placed around the limbus, and the AM was anchored to both the upper and lower lid margins by running sutures. All five cases reported herein did not experience such a complication. Additional clinical studies may be necessary to confirm the perceived advantage of these running sutures.

The most notable findings observed in these five cases were that intractable ocular pain subsided immediately after surgery and ocular inflammation was rapidly reduced. Rapid pain relief is a benefit of using the AM as a patch. However, the precise mechanism of this pain relief has not been elucidated yet. Reducing inflammation is a key to promoting epithelialization. As a result, a vicious cycle leading to scarring sequelae and severe visual loss can be avoided. This anti-inflammatory effect may be mediated in part by the antiproteases present in the $\mathrm{AM}^{14}$ and in part by the suppression of IL-1 release. ${ }^{15}$ It remains unclear whether such an 
anti-inflammatory effect is also directly responsible for the subsequent rapid re-epithelialization. It should be noted that the AM contains growth-promoting mitogens that may be important in promoting re-epithelialization. ${ }^{16}$ Collectively, these observations may explain why symblepharon is not a common outcome in our patients and in those reported by Meller et al. ${ }^{2}$ As reported by Kim et al, ${ }^{1}$ this mode of using AM may be applicable in the future towards treating other difficult ocular surface disorders characterized by recalcitrant inflammation and poor epithelial wound healing.

In this report, Cases 3 and 5 clearly demonstrated the remarkable effect of AMP that promoted rapid epithelialization and prevented such sequelae as symblepharon and scarring. However, mild conjunctival ingrowth inferiorly, suggestive of partial corneal limbal stem cell deficiency, was observed in Case 3 (Figure 3e and f). Cases 1, 2 and 4 were relatively mild and the conventional therapy could have produced a good prognosis. Nevertheless, in the light of the fact that there was a large defect involving both the cornea and the conjunctiva, the healing of the former with a BSCL might have left the latter with a symblepharon. Even if the grading is II, an unfavourable outcome has been reported as persistent corneal epithelial defect, corneal opacity, and entropion. ${ }^{17}$

Although we have not yet observed any downsides of $\mathrm{AMP}$, it is not a panacea for extremely severe burns. In such cases, a combination with other therapies such as glued-on contact lens, ${ }^{18}$ tenoplasty, ${ }^{19}$ limbal stem cell transplantation, ${ }^{20-23}$ transplantation of the corneal epithelial sheet cultured on $3 \mathrm{~T}^{24}$ and $\mathrm{AM}^{25,26}$ or alternative therapies might be needed.

In conclusion, immediate AMP is quite effective for treating acute chemical burns of moderate severity, especially for those showing shallow but wide corneal and conjunctival defects.

\section{Acknowledgements}

Proprietary interest: SCGT has obtained a patent on the preparation and clinical uses of human amniotic membranes. The other authors do not have any financial interest in amniotic membranes.

\section{References}

1 Kim JS, Kim JC, Na BK, Jeong JM, Song CY. Amniotic membrane patching promotes healing and inhibits protease activity on wound healing following acute corneal alkali burns. Exp Eye Res 2000; 70: 329-337.

2 Meller D, Pires RTF, Mack RJS, Figueiredo F, Heiligenhaus A, Park WC et al. Amniotic membrane transplantation for acute chemical or thermal burns. Ophthalmology 2000; 107: 980-990.
3 Sridhar MS, Bansal AK, Sangwan VS, Rao GN. Amniotic membrane transplantation in acute chemical and thermal injury. Am J Ophthalmol 2000; 130: 134-137.

4 Roper-Hall MJ. Thermal and chemical burns. Trans Ophthalmol Soc UK 1965; 85: 631-640.

5 Lee S-H, Tseng SCG. Amniotic membrane transplantation for persistent epithelial defects with ulceration. Am J Ophthalmol 1997; 123: 303-312.

6 Tseng SCG, Prabhasawat P, Lee S-H. Amniotic membrane transplantation for conjunctival surface reconstruction. Am J Ophthalmol 1997; 124: 765-774.

7 Tseng SCG, Prabhasawat P, Barton K, Gray T, Meller D. Amniotic membrane transplantation with or without limbal allografts for corneal surface reconstruction in patients with limbal stem cell deficiency. Arch Ophthalmol 1998; 116: 431-441.

8 Wagoner MD. Chemical injuries of the eye: current concepts in pathophysiology and therapy. Surv Ophthalmol 1997; 41: 275-313.

9 Sorsby A, Symons HM. Amniotic membrane grafts in caustic burns of the eye. Br J Ophthalmol 1946; 30: 337-345.

10 Sorsby A, Haythorne J, Reed H. Further experience with amniotic membrane grafts in caustic burns of the eye. Br J Ophthalmol 1947; 31: 409-418.

11 Sorsby A. Amniotic membrane grafts in burns. In: Sorsby A (ed). Modern Trends in Ophthalmology. Paul B. Hoeber, Inc.: New York, 1947, pp 504-510.

12 Hughes Jr WF. Alkali burns of the eye. II. Clinical and pathologic course. Arch Ophthalmol 1946; 36: 189-214.

13 Hughes Jr WF. Alkali burns of the cornea. I. Review of the literature and summary of present knowledge. Arch Ophthalmol 1946; 35: 423-449.

14 Hao Y, Ma DH-K, Hwang DG, Kim WS, Zhang F. Identification of antiangiogenic and antiinflammatory proteins in human amniotic membrane. Cornea 2000; 19: 348-352.

15 Solomon A, Rosenblatt M, Monroy D, Ji Z, Pflugfelder SC, Tseng SCG. Suppression of interleukin- $1 \alpha$ and interleukin-1 $\beta$ expressed by human corneal epithelial cells cultured on the amniotic membrane stromal matrix. Br J Ophthalmol 2001; 85: 444-449.

16 Koizumi N, Inatomi T, Sotozono C, Fullwood NJ, Quantock AJ, Kinoshita S. Growth factor mRNA and protein in preserved human amniotic membrane. Curr Eye Res 2000; 20: 173-177.

17 Davis AR, Ali QK, Aclimandos WA, Hunter PA, Ali QH. Topical steroid use in the treatment of ocular alkali burns. Br J Ophthalmol 1997; 81: 732-734.

18 Kenyon KR, Berman M, Rose J, Gage J. Prevention of stromal ulceration in the alkali-burned rabbit cornea by glued-on contact lens. Evidence for the role of polymorphonuclear leukocytes in collagen degradation. Invest Ophthalmol Vis Sci 1979; 18: 570-587.

19 Teping C, Reim M. Tenonplasty as a new surgical principle in the early treatment of the most severe chemical eye burns. Klin Monatsbl Augenheilkd 1989; 194: 1-5.

20 Kenyon KR. Limbal autograft transplantation for chemical and thermal burns. Dev Ophthalmol 1989; 18: 53-58.

21 Kruse FE, Kach JM, Klein U, Rohrschneider K, Vokker HE, Waubke TN. The importance of limbal stem cells for the therapy of chemical burns. Ger J Ophthalmol 1993; 2: 289.

22 Morgan S, Murray A. Limbal autotransplantation in the acute and chronic phases of severe chemical injuries. Eye 1996; 10: 349-354. 
23 Theng JTS, Tan DTH. Combined penetrating keratoplasty and limbal allograft transplantation for severe corneal burns. Ophthalm Surg Lasers 1997; 28: 765-768.

24 Pellegrini G, Traverso CE, Franzi AT, Zingirian M, Cancedda R, De Luca M. Long-term restoration of damaged corneal surface with autologous cultivated corneal epithelium. Lancet 1997; 349: 990-993.
25 Tsai RJF, Li L-M, Chen J-K. Reconstruction of damaged corneas by transplantation of autologous limbal epithelial cells. N Engl J Med 2000; 343: 86-93.

26 Koizumi N, Inatomi T, Suzuki T, Sotozono C, Kinoshita S. Cultivated corneal epithelial stem cell transplantation in ocular surface disorders. Ophthalmology 2001; 108: 1569-1574. 